Educando en investigación y desarrollo sostenible

Una breve reflexión desde la exigencia universal de protección de los derechos bumanos

\title{
Education for Research and Sustainable Development
} A brief reflection from the universal need to protect the human rights

F. Mariño Menéndez* http://dx.doi.org/10.21503/lex.v12i14.614

\footnotetext{
* Profesor en la Universidad Carlos III de Madrid.
}

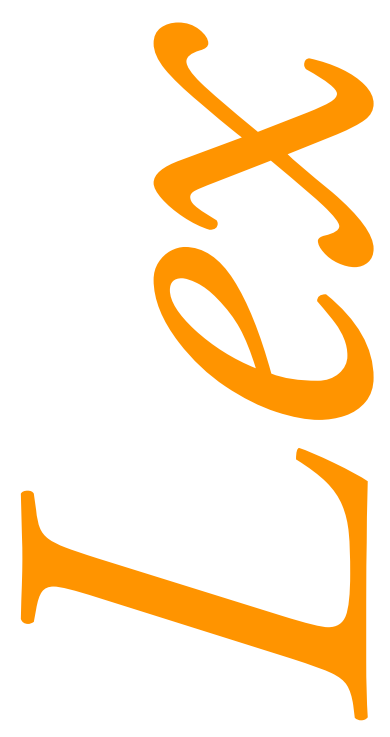




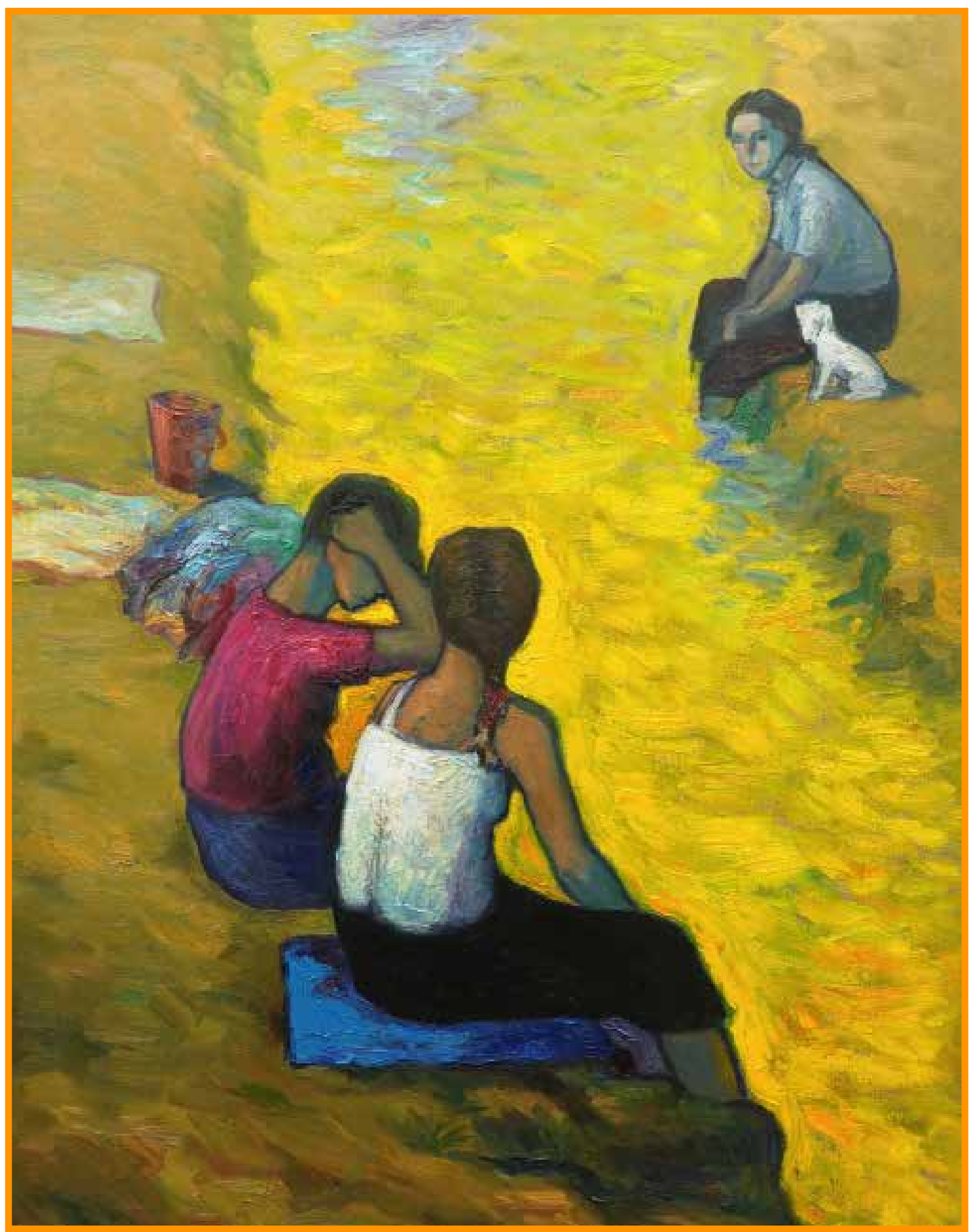

Atardecer en el río. Óleo sobre tela $(120 \times 90 \mathrm{~cm})$. 


\section{RESUMEN}

El presente artículo reproduce los principales puntos de una ponencia presentada en torno del tema de la educación universitaria vinculada con la necesidad perentoria de garantizar la protección de los derechos humanos. En realidad de lo que se trata es de proponer el camino que debe trazarse la educación universitaria para, al mismo tiempo que los estudiantes internalizan los valores universales rectores de la convivencia civilizada entre los hombres de todas las naciones, alcanzar uno de sus principales objetivos: formar personas realizadas en el campo de su actividad profesional al mismo tiempo que defensoras del sistema internacional de protección de los derechos humanos, condición indispensable para garantizar un efectivo desarrollo sostenible.

Palabras clave: derechos humanos, educación universitaria, democracia, desarrollo sostenible.

\section{ABSTRACT}

This article reproduces the main points of a presentation around the theme of higher education related to the urgent need to ensure the protection of human rights. Actually, it is to propose the way to draw the university education, while students internalize the governing of civilized coexistence among men of all nations universal values, achieving one of its main objectives: train people made in the field of professional activity while defenders of the international system of protection of human rights, essential to ensure effective sustainable development.

Key words: human rights, university education, democracy, sustainable development. 

1. La Universidad como centro principal y superior de docencia e investigación de las ciencias sociales y jurídicas y de la formación de un espíritu crítico y humanista. Los valores fundamentales de la actividad universitaria y su transmisión a los estudiantes.

La que el filósofo español José Ortega y Gasset denominó Misión de la Universidad es entendida en la gran tradición de origen europeo, principalmente la continental, como "enseñanza superior", es decir, como impartición de conocimientos y realización de investigaciones por profesores ya formados, con el objetivo de, a su vez, formar expertos en campos del saber y, al mismo tiempo, moldearlos con el espíritu propio de los ciudadanos ilustrados. Esta expresión significa formar personas dotadas de espíritu crítico frente al poder y frente a todo tipo de dogmatismos, científicos u otros, que puedan limitar el ejercicio en libertad, de acuerdo con las Leyes de la República, de sus mejores capacidades, para contribuir así al progreso de su nación y, por ello, al de la humanidad.

Es este un ideal de la Ilustración europea y americana, hija de la anterior, cuyos frutos han sido a veces espléndidos y a veces decepcionantes, según si los grupos de interés y de poder (incluido en ocasiones los del propio Poder de las instancias del Estado) hayan o no logrado limitar la crítica constructiva de la ciencia oficial y de los demás conocimientos establecidos, o limitar incluso las propuestas para reformar el funcionamiento de las propias instituciones públicas, hechas sobre la base de los valores del patriotismo constitucional, según la conocida expresión de Jürgen Habermas

Si bien, a mi juicio, la Universidad pública tiene un papel insustituible y esencial en el logro de los anteriores ideales, tal afirmación no disminuye en modo alguno las contribuciones de las universidades privadas. Hasta hoy, en una vieja tradición que se remonta incluso a la época colonial, las universidades de la Iglesia u otras privadas han hecho y continúan realizando muy valiosas aportaciones al conocimiento y a la enseñanza críticos de la realidad social, en defensa de los valores más universales y, en definitiva, de la formación de ciudadanos más y más cabales. 
2. El respeto, la protección eficaz y el logro del goce efectivo de los derechos humanos como horizonte ético, político y jurídico de la enseñanza universitaria de las ciencias sociales y jurídicas.

Las generalmente denominadas hoy en día "ciencias sociales y jurídicas" comprenden señaladamente la Filosofía, la Historia, el Derecho, la Economía, la Sociología y la Antropología, cuyos contenidos podemos aquí considerar ampliamente tópicos al margen de escuelas de pensamiento y de organizaciones particulares de su docencia. Lo que la unidad del conocimiento rechaza sin más es que aquellas ciencias constituyan un modo de compartimiento estanco respecto a las ciencias de la naturaleza o las ciencias de la ingeniera y otras aplicadas, y menos aún a las enseñanzas artísticas.

De un modo u otro, las concepciones, teorías y articulaciones conceptuales de todas estas — cada una en su ámbito - se han interfecundado con metodologías y logros de las ciencias sociales y jurídicas, de modo que en núcleos determinados constituyen verdaderos "saberes universales".

De ahí que la auténtica formación universitaria, en cualquiera de sus conocimientos, deba colocar en su centro el ideal de una enseñanza crítica, es decir, integral, que además debería haber sido fundamentada previamente en la enseñanza media.

El núcleo troncal de la enseñanza universitaria debe atender a ese ideal por más que convenga armonizar tal finalidad con la necesaria especialización, en diferentes formas, propias de los diversos grados, licenciaturas, diplomaturas y, subsidiariamente, maestrías, posgrados y doctorados.

A la luz de las consideraciones anteriores, ese ideal aplicado en la práctica al conocimiento, la investigación, la enseñanza y, en definitiva, a la formación teórica y práctica en el ámbito de los derechos humanos se ha convertido en un elemento fundamental de la actividad universitaria, del mismo que la promoción y la protección de los derechos humanos, su normativa y sus garantías se han convertido en el horizonte axiológico universal de la sociedad internacional contemporánea y de su comunidad internacional.

3. Los logros en la promoción y protección de los derechos humanos como progreso de la conciencia jurídica común de la humanidad. Perspectiva histórica.

En efecto, la dignidad de la persona como valor supremo de las sociedades humanas fue desde luego formulada como tal desde siglos remotos por las grandes religiones y escuelas nobles de pensamiento, en particular por la tradición cristiana. En cierto modo, pues, ha formado siempre parte de lo que Leibniz hubiera denominado "filosofía perennis", en la que tal dignidad última residiría en la identificación del Yo personal con el propio Ser divino. 
Pero más acá de esas reflexiones, lo cierto es que, dentro de los avatares de la historia de la humanidad, solo en el siglo XX se han puesto las bases para que en, el orden internacional universal, los derechos humanos y libertades fundamentales, en los que cobra expresión positiva la señalada dignidad de la persona, hayan sido por fin formulados de algún modo por la comunidad internacional organizada y su protección haya comenzado, en sintonía con la protección ofrecida por los ordenamientos estatales, cuando es el caso.

Están desde luego los antecedentes históricas de la prohibición definitiva de la esclavitud y del trafico de esclavos durante el siglo XIX, al igual que las primeras normas internacionales del Derecho Humanitario, de la protección de las minorías y de la protección de los derechos de los trabajadores, esta última con la creación de la OIT en 1919.

Pero tras los indecibles horrores de la Segunda Guerra Mundial, la conciencia jurídica de la humanidad (una humanidad aún parcial, deberíamos decir) dio por así decir un salto cualitativo, y la comunidad internacional dejó de considerar que el trato que un Estado diera a sus nacionales u otras personas sometidas a su gobierno constituyera un "asunto de la jurisdicción exclusiva interna”.

Entonces, tras la adopción de la Carta de las Naciones Unidas y la creación de la Comisión de Derechos Humanos fueron adoptados los primeros instrumentos de alcance universal, como la Convención contra el Genocidio y la Declaración Universal de Derechos Humanos, ambas de 1948. Sobre esa base inicial, otros logros regionales internacionales, como la formulación de normas constitucionales internas, el avance imparable de la descolonización y la articulación de un sistema universal de promoción y protección de los derechos humanos, han dado cuerpo a todo un sector del orden jurídico internacional: el Derecho Internacional de los Derechos Humanos, probablemente el más vinculado, junto con el relativo a la prohibición del uso de la fuerza armada por los Estados, a la constitución material y al orden público de la comunidad internacional.

4. Universalidad, indivisibilidad e interdependencia de los derechos humanos fundamentales. Particularidades culturales y políticas. La interacción entre los valores de la democracia, del Estado de derecho y de la protección efectiva de los derechos humanos.

La dicotomía entre derechos humanos civiles y políticos, por una parte, y derechos económicos sociales y culturales, por otra, inspiró, como se sabe, la adopción de los dos Pactos Internacionales de Derechos Humanos de las Naciones Unidas, en vigor desde 1976. Pero ya en la Conferencia de Derechos Humanos de Teherán (1968), y muy particularmente en la Declaración adoptada por la Conferencia de Viena (1993), todos los derechos humanos se consideran universales, indivisibles e interdependientes, aun si se tienen cuenta las particularidades culturales y religiosas propias de ciertos países. La protección efectiva de 
determinadas libertades y determinados derechos humanos es inseparable de la realización de la democracia como orden jurídico-político que da a las pueblos el protagonismo de su propia historia y destierra las tiranías y las dictaduras de toda clase. Así, cabe afirmar que ciertos derechos humanos son inderogables absolutamente, es decir, están protegidos por normas imperativas del Derecho Internacional. Así mismo, se considera que la libre elección periódica de los gobernantes es inseparable de las libertades de reunión, manifestación y expresión; que la pobreza es incompatible con el goce real de los derechos civiles, y que la corrupción y la falta de independencia del poder judicial impiden que un Estado de derecho afirme y haga efectivos los derechos humanos.

No es mi propósito aquí hacer enumeraciones de derechos o insistir en que solo la protección de todos ellos simultáneamente permite un desarrollo humano. Sí diré que en el seno de la comunidad internacional no prevalece el valor de la solidaridad en una formulación general de Derecho Positivo. Además, no existe un único modelo de democracia universalmente aceptada, y la defensa de la soberanía, legítima como es, puede convertirse un una coartada para garantizar la impunidad de los responsables de las violaciones más graves de los derechos humanos.

5. El desarrollo del sistema universal de protección de derechos humanos particularmente en el marco de las Naciones Unidas.

El Derecho Internacional de los Derechos Humanos se articula en torno a determinados principios generales, todos los cuales emanan del último y más fundamental del respeto a la dignidad de la persona. Estos son el Principio de igualdad y no discriminación, el Principio (ya aludido) de inderogabilidad del núcleo duro de orden público (que incluye los derechos de acceso a la justicia, a un proceso debido, a no ser privado arbitrariamente de la vida, a no ser sometido a tortura o desaparición forzada o ser tomado como rehén, y a no ser sometido a esclavitud o servidumbre), el Principio que exige la satisfacción de las necesidades básicas del ser humano: alimentación suficiente y agua potable, vivienda digna, educación y atención sanitaria, además del Principio de humanidad en tiempo de conflictos armados, el Principio de protección particular de personas y colectivos vulnerables, el Principio de responsabilidad individual internacional penal por crímenes internacionales, y el Principio de responsabilidad internacional de los Estados frente a la comunidad internacional por violaciones graves

Pero el sistema universalmente organizado de protección de derechos humanos comprende además la adopción de, por lo menos, las diez grandes convenciones internacionales de derechos humanos de Naciones Unidas, y un entramado de órganos especializados a cuyo frente se encuentran hoy, de una parte, el Alto Comisionado de Naciones Unidas para los derechos humanos y, de otra, el Consejo de Derechos Humanos, al que rinden cuentas sus relatores especiales y ante el cual se desarrolla el denominado Examen Periódico Universal de la situación de los derechos humanos en cualquier lugar del mundo. 
6. El desarrollo sostenible es una denominación que aúna la exigencia de la eliminación de la pobreza y de la participación equitativa de todos los Estados en los beneficios de la producción, intercambio u consumo de bienes y servicios a escala global sin discriminación, junto a la exigencia de respetar el equilibrio de los ecosistemas de la tierra y la integridad de la biosfera.

El derecho al desarrollo como derecho humano ha sido formulado por la Asamblea General de las Naciones Unidas en términos rotundos, y no es necesario hacer aquí un balance del proceso histórico de la acción del sistema de la ONU, de sus organismos, sus órganos especializados y sus conferencias diplomáticas en favor del desarrollo sostenible. Las metas más concretas en lo que se refiere a la satisfacción de las necesidades básicas fueron quizá formuladas por la Declaración del Milenio (2000). Por su parte, el Programa de las Naciones Unidas para el Desarrollo (PNUD) ha elaborado una serie de índices de desarrollo humano que coloca la eliminación de la pobreza extrema, la igualdad entre el hombre y la mujer, la longevidad alcanzada y la eliminación del analfabetismo entre las metas de alcance exigible con urgencia.

Ese horizonte axiológico y de actuación es para todos los sujetos del orden internacional, y conlleva e implica una obligación general de todos los Estados de cooperar, según su grado de desarrollo, entre sí y con la comunidad internacional para llegar a su progresiva realización.

El conocimiento de los derechos humanos, de sus normas e instancias protectoras y de las formas de su protección constituye una exigencia ineludible de la formación universitaria. La Universidad, como fuente del saber crítico y lugar de formación de ciudadanos conscientes, tiene como deber la investigación y la enseñanza de los derechos humanos, dentro de sus posibilidades materiales y humanas y sus especializaciones. Solo así la utopía, ideal pero concreta de un orden mundial más justo y sin guerras puede encontrar los espíritus dispuestos a apoyarla en la medida de sus capacidades. 